\title{
Más allá de la adaptación. Assassin’s Creed y los mundos transmediales
}

\section{Beyond Adaptation. Assassin's Creed and Transmedia Worlds}

\author{
MARTA FERNÁNDEZ-RUIZ \\ Universidad Politécnica de Cataluña \\ martafernandezruiz@gmail.com \\ ORCID ID: 0000-0002-3004-3242
}

\begin{abstract}
Resumen: La convergencia mediática y la expansión de las ficciones en distintas plataformas han dado lugar a que mundos de ficción que tenían su origen en el videojuego se hayan desarrollado en otros medios, en un contexto en que las audiencias migran de unas plataformas a otras con tal de entrar en contacto con sus universos de ficción favoritos. Este trabajo tiene como objeto el estudio de la saga de videojuegos Assassin's Creed y la expansión transmedia que se ha llevado a cabo a través de otras plataformas. Para ello se procedió al análisis de contenido del videojuego Assassin's Creed II, la película Assassin's Creed y el cómic Assassin's Creed: Reflexiones \#1, desde la perspectiva de los fundamentos de los Mundos Transmediales y las propiedades y tipos de experiencia que ofrece de cada medio.
\end{abstract}

Palabras clave: cómics, videojuegos, transmedia, Assassin's Creed.

\begin{abstract}
Media convergence and the expansion of fictions in different platforms has led to the development of fictional worlds born in video games and extended along other platforms, in a context in which audiences migrate from one platform to another in order to get in touch with their favorite fictional universes. The purpose of this work is to study the Assassin's Creed video game saga and the transmedia expansion that has taken place through other platforms. To do so, we proceeded to the content analysis of the video game Assassin's Creed II, the movie Assassin's Creed and the comic Assassin's Creed: Reflections \#1, from the perspective of the fundamentals of Transmedia Worlds and the affordances and experiences that each medium offers.
\end{abstract}

Key words: comics, videogames, transmedia, Assassin's Creed. 


\section{INTRODUCCIÓN}

Assassin's Creed (Ubisoft, 2007) es una de las sagas más emblemáticas del estudio multinacional Ubisoft, dedicado a la producción y desarrollo de videojuegos. Se trata de una serie de videojuegos caracterizados por permitir al jugador revisitar diferentes épocas históricas al tiempo que experimenta una historia de ciencia ficción por la que personajes contemporáneos se conectan con experiencias de sus antepasados por medio de un dispositivo tecnológico llamado Animus.

Bajo el eslogan History Is Our Playground, si algo ha llamado la atención de Assassin's Creed desde el punto de vista académico ha sido su forma de reconstruir épocas pasadas y de aproximarse a hechos y personajes históricos. En este sentido, Westin y Hedlun (2016) consideran que no es el rigor histórico lo que hace destacar la saga, sino el hecho de que se trata de una fidelidad histórica negociada, más cercana a la memoria.

Además de este rasgo, se puede afirmar que Assassin's Creed es un ejemplo significativo del ecosistema mediático actual, caracterizado por la adaptación y la expansión de ficciones y experiencias culturales a través de diferentes plataformas, así como por la convergencia existente entre nuevos y antiguos medios junto al comportamiento migratorio de las audiencias, que van allá donde sea necesario para buscar experiencias de entretenimiento relacionadas con sus mundos de ficción favoritos (Jenkins, 2006, Scolari, 2015). La saga Assassin's Creed ha visto su universo de ficción expandido en una película, diferentes series de historietas, libros, recorridos virtuales y diversos contenidos generados por los usuarios y fans, como la posibilidad de crear niveles personalizados en el editor de niveles proporcionado por Ubisoft en el marco del lanzamiento de Assassin's Creed Oddyssey (Ubisoft, 2018).

$\mathrm{Al}$ mismo tiempo, largas han sido las conversaciones en torno a las relaciones existentes entre videojuegos y cine (King y Krzywinska, 2002). En ellas se abordan las influencias que el cine ha ejercido en el lenguaje del videojuego a través del concepto de remediación, acuñado por David Jay Bolter y Peter Grusin para hacer referencia a la lógica formal por la que nuevos medios retoman la estética de medios previos (2000). Otras han ahondado en cuestiones que tienen que ver con el fracaso de distintas adaptaciones de videojuegos llevadas al cine (Villalobos, 2016), y otras han adoptado enfoques más innovadores hacia la propia faceta lúdica del cine (Navarro, 2019).

Por otra parte, el interés de las industrias culturales y los prosumidores hacia la convergencia entre cine, cómic y videojuegos es palpable y se puede constatar en diferentes hechos. El mercado 3D Wire, celebrado anualmente en Segovia y enfocado tradicionalmente en la animación y los videojuegos 2D y 3D, anunció durante el año 2019 su transformación en un mercado cuyo nombre sería WEIRD y abriría su ámbito de actuación para poder dar cabida a la imagen estática y a las viñetas de los cómics. 
Asimismo, se llevó a cabo la publicación, por parte de Norma Editorial, de un libro del arte del videojuego Gris (2018, Nómada Studio) que, lejos de obedecer al formato estricto de libro de arte, es «más bien un cómic mudo, un storyboard gigantesco, dividido entre capítulos, que permite apreciar al lector, sin necesidad de usar ni una palabra, el viaje de exploración seguido en el videojuego» (Sucasas, 2020).

En este contexto, este artículo presenta una reflexión en torno a la narrativa transmedia en el marco de la saga Assassin's Creed a través de la revisión de uno de sus videojuegos (Assassin's Creed 2, Ubisoft, 2009), la película de Justin Kurzel (Assassin's Creed, 2016) y uno de los cómics de Ian Edginton y Valeria Favoccia (Assassin's Creed: Reflexiones \#1, 2017). Para ello, se aborda el concepto de mundo transmedia desarrollado por Susana Tosca y Lisbeth Klastrup (2019), así como las diferentes affordances o propiedades que cada medio (videojuego, película y cómic) aporta a la expansión del mundo transmedia específico de Assassin's Creed. También se trabaja desde la consideración de que en el ámbito transmedia no se cuenta la misma historia en cada medio, sino que se desarrolla una narrativa que abarca diferentes medios y lenguajes (Scolari, 2013). Asimismo, la reflexión también se lleva a cabo tomando como referencia el concepto de remediación de Bolder y Grusin (2000).

\section{MUNDOS TRANSMEDIALES}

En el contexto actual de convergencia mediática, es necesario puntualizar que transmedia no es lo mismo que crossmedia o adaptación. De acuerdo con Linda Hutcheon (2006), una adaptación es una transposición o alteración abiertamente anunciada de otro trabajo o conjuntos de trabajos. Es, asimismo, una apropiación creativa e interpretativa de un trabajo previo por parte del creador. Y finalmente, es una forma de relacionarse con un texto mediante mecanismos intertextuales a través de la interpretación del usuario o receptor. Tampoco es lo mismo que multimedia. Si bien el término multimedia hace referencia al movimiento centrípeto de concentración de lenguajes y medios en una única interfaz, la palabra transmedia alude al movimiento centrífugo que expande una narrativa en muchos medios y plataformas con la complicidad de los prosumidores (Scolari, 2019). La expansión de un universo narrativo en diferentes plataformas obedece en parte a la inquietud por producir una mayor inmersión del consumidor/usuario/fan en el universo de ficción. En función de cómo se concibe un proyecto de ficción desde un inicio, es posible hablar de proyectos transmedia proactivos (concebidos como transmedia desde el comienzo de su planificación) o reactivos (ideados como tal sobre la marcha) (Scolari, 2013).

El estudio de la narratología en los videojuegos ha adoptado una posición cercana a los mundos de ficción como alternativa a la senda estructuralista. En este sentido, se ha rescatado el concepto de mundos historia (Herman, 2002), definido como aquellas representaciones 
mentales que permiten al receptor inferir detalles de situaciones, personajes y eventos, que pueden ser implícita o explícitamente mencionados en un texto o discurso narrativo. De manera similar, los mundos transmediales son definidos por Tosca y Klastrup (2019) como aquellos actos de imaginación e imágenes mentales construidas gradualmente a partir de diversos encuentros con ficciones que comparten el mismo universo, y que llegan a existir en actos de recepción estética.

Tosca y Klastrup parten de diversas teorías acerca de la incompletitud de las ficciones (Iser, 1978; Eco, 1979). Los usuarios (lectores, jugadores, etc.) necesitan llevar a cabo un trabajo interpretativo y emocional para experimentar de manera estética la narrativa con la que interactúan. Para las investigadoras, la experiencia de visionar una película perteneciente a un enorme mundo transmedia, como El señor de los Anillos (Lord of the rings), es un proceso complejo donde el receptor interpreta, se involucra emocionalmente y accede a sus recuerdos o al repertorio precedente de conocimientos sobre este universo transmedia que ha ido desarrollando a lo largo de su vida como lector, espectador, consumidor o usuario. No solo reacciona a las escenas de la película, sino que relaciona esas escenas con el resto de sus conocimientos acerca del mundo, así como con lo que el resto de la comunidad de fans opina y sabe acerca de este mundo.

Para describir este proceso utilizan tres conceptos:

- Mythos: historias de fondo que explican los mundos transmediales.

- Topos: escenarios (lugares y gentes).

- Ethos: filosofía y ética que tienen sentido en ese mundo.

Cualquier encuentro con un producto transmedia evoca todo el conocimiento y afecto que el usuario asocia con el mundo transmedial en que dicho producto se encuentra situado. Este conocimiento y afecto se reordenará con cada encuentro. La experiencia transmedia es, por tanto, la actualización que realiza un usuario del mythos, topos y ethos del mundo transmedial, que se ha manifestado en una plataforma determinada con sus correspondientes affordances (posibilidades específicas que ofrece cada plataforma o medio de comunicación).

Por tanto, la experiencia transmedia siempre es situada, tanto en tiempo (en relación con previos y futuros encuentros con mundos transmediales), en espacio (la materialidad del medio también juega una parte importante) y en el cuerpo del usuario (que se involucra sensorial, intelectual y emocionalmente).

\section{EL UNIVERSO ASSASSIN'S CREED}

La saga Assassin's Creed acumula más de una década de trayectoria y es uno de los títulos más populares de los videojuegos ambientados en el pasado. La serie se ha desarrollado en épocas que van desde el Egipto Helenístico al Londres de la era victoriana, pasando por la Guerra del Peloponeso en Grecia, la Tercera Cruzada o la Revolución Francesa. A lo 
largo de los años ha evolucionado introduciendo nuevas mecánicas y mejorando aspectos de experiencia de usuario e interfaz gráfica (Chalfoun y Dankoff, 2018).

A pesar de que las ambientaciones en diferentes períodos históricos forman parte de la esencia de la saga, los juegos giran en torno a una historia de fondo principal, que es la de la guerra secreta que abarca milenios y continúa en la era moderna entre la Orden de los Templarios y la Hermandad de los Asesinos.

Los Templarios buscan la paz en el mundo, si bien su interpretación de lo que es un mundo perfecto se basa en ejercer un control absoluto sobre la civilización y una eliminación radical del libre albedrío en el ser humano. La Orden se manifiesta en la época actual bajo el conglomerado corporativo multinacional Industrias Abstergo.

La Hermandad de los Asesinos, contraria a estos principios, lucha por la libertad y se guía por l Credo, un código ético que niega la existencia de una verdad absoluta y que busca que los individuos sean dueños de sí mismos. El código prioriza la sabiduría por encima de las restricciones morales de los hombres y establece tres normas: no asesinar a inocentes, actuar de manera sigilosa (en las sombras) y no comprometer a la Hermandad. Estas bases filosóficas se asientan en la primera entrega de la saga, Assassin's Creed I (Ubisoft, 2007).

Abstergo cuenta con una tecnología (si bien los Asesinos conseguirán replicarla y utilizarla por su cuenta) que permite a los Asesinos de la época actual acceder a las memorias de sus antepasados. Se trata del Animus, un dispositivo por el que los jugadores pueden visitar, pero no cambiar de manera sustancial, el pasado. El Animus es, por tanto, el nexo de conexión entre la guerra secreta y milenaria librada entre la Orden de los Templarios y la Hermandad de Asesinos, por una parte, y los lugares y períodos históricos a los que cada videojuego transporta al jugador, por otra.

Tanto en la época actual como en los distintos pasajes históricos, la saga muestra personajes carismáticos que perduran en distintos videojuegos. Por ejemplo, la saga de Ubisoft comienza con Desmond Miles, quien conecta con dos de los antepasados más populares del juego: Altaïr Ibn LaAhad y Ezio Auditore.

Asimismo, los videojuegos giran en torno a unas mecánicas de juego que conforman uno de los elementos identitarios de la saga. Se puede considerar que la saga se inscribe dentro del género de acción-aventura en tercera persona. Los jugadores tienen acceso a tres tipos principales de actividades: la lucha (modalidades cuerpo a cuerpo o a distancia), el sigilo, y el parkour (trepar, saltar y correr a través de muros, azoteas y otras partes de diferentes edificios y monumentos populares). 


\section{ASSASSIN'S CREED II, EXPLORACIÓN Y ACCIÓN}

Assassin's Creed II comienza en la época actual con Desmond Miles, el Assasin que en Assassin's Creed I había sido retenido por Abstergo para obtener información de uno de sus antepasados, Altaïr Ibn La-Ahad, a través del Animus. En esta ocasión, Desmond escapa de Abstergo ayudado por otros asesinos y, a través de una nueva versión de Animus controlada por estos, comienza a revivir la memoria genética de otro antepasado, Ezio Auditore, quien vivió en Italia durante el Renacimiento a finales del siglo XV (1459-1499). Esta visita al pasado permite al jugador entrar en contacto con personajes y acontecimientos históricos como Leonardo Da Vinci (quien en repetidas ocasiones ayuda a Ezio a conseguir sus objetivos), Lorenzo de Medici, así como con las distintas intrigas de la familia Borgia.

En el videojuego, el descubrimiento de la historia está unido a la progresión en el juego y a la adquisición de habilidades, como mejorar en sigilo o aprender a trepar para transitar por rincones que permitan a Ezio no ser descubierto por los enemigos. Una de las principales maneras por las que se promueve el progreso en el juego es la de proporcionar al jugador (y a Ezio) información a través de las cinemáticas o cut scenes, definidas por King y Krzywinska (2002) como secuencias pre-renderizadas (a diferencia de los frames específicos de las secuencias de juego, procesados en tiempo real), en las que el jugador adopta el papel de observador. Las cinemáticas dotan de contexto y significado a las interacciones del jugador (Klevjer, 2002). Desde el punto de vista de la noción de remediación, las cinemáticas conforman uno de los principales elementos de conexión entre el lenguaje cinematográfico y el videolúdico, en tanto que a través de esta, un medio precedente (el cine) se encuentra inserto en un medio más reciente (en este caso, el videojuego). En Assassin's Creed II es posible ver cut scenes introductorias que presentan personajes y escenarios, así como el principal conflicto de la historia del juego, y también cut scenes que indican las misiones y objetivos que el jugador debe cumplir. No es extraño encontrar cinemáticas en las que un personaje advierte a Ezio que no es momento de luchar, sino que debe salir corriendo, instando al jugador a tomar la estrategia de reservar sus recursos para más tarde.

A pesar de esta influencia claramente cinematográfica, Assassin's Creed II guarda una fuerte conexión con antiguas formas narrativas en las que el argumento es desvelado a partir del movimiento del héroe principal a través de un espacio o entorno. Como advierte Manovich (2005), la espacialidad y la navegación a través del espacio tridimensional es esencial, si no la affordance clave de la experiencia de juego. Antes de alcanzar el final de la narrativa de un videojuego, el jugador debe visitar gran parte del mismo, descubriendo su geometría y topología, aprendiendo sus aspectos lógicos y sus secretos.

La capacidad de visitar de manera virtual otro lugar y período histórico en el juego conecta, además de con la noción de espacialidad como 
affordance, con la metáfora del parque temático o parque de atracciones. En este sentido, no han sido pocos quienes han identificado conexiones entre la experiencia de jugar a un videojuego con la de visitar un parque temático (Pearce, 2007; Jenkins, 2004; Murray, 1999). Basta ver una descripción que Janet Murray hacía en los años 90 sobre la atracción Aladino de Walt Disney World para identificar la similitud existente entre ambas experiencias:

Los visitantes se sienten atraídos por la ciudad con sus minaretes, los misterios de sus callejones y la presencia de personajes animados. El visitante tiene un papel en la historia, y sus movimientos están motivados por la tarea de encontrar el escarabajo escondido. El modelo de Aladino sugiere que es posible hacer una nueva forma de montar en las películas: una aventura estructurada en torno a la curiosidad de los visitantes y la belleza del mundo a explorar (Murray, 1999: 60).

Assassin's Creed II supone una aventura estructurada en torno a la curiosidad del jugador por explorar la belleza y majestuosidad de ciudades como Venecia o Florencia, así como adentrarse en monumentos y edificios emblemáticos como Il Duomo, un edificio que el jugador no solo puede explorar y contemplar, sino sobre el que literalmente puede trepar.

Autores como Nitsche (2008) han advertido esta conexión entre el videojuego, la espacialidad y la representación visual del espacio con distintos grados de interactividad. El espacio del videojuego es visualizado a través de una cámara, si bien esta cámara muestra la acción de una manera muy diferente a la del cine. Los jugadores tienen control sobre la misma durante la mayor parte de las sesiones de juego, y entran en un mundo continuo, navegable y diegético, como si fuese el escenario de un rodaje infinito. El jugador experimenta los espacios del juego como una combinación de un espacio navegable (urbanismo y arquitectura) y un espacio cinematográfico (cine).

Una combinación interesante entre aspectos cinemáticos e interacción con el entorno se percibe cuando Ezio sube a las atalayas. Subir las atalayas en Assassin's Creed II es una interacción con el entorno y una mecánica, y se recompensa con una cinemática que muestra al jugador una panorámica completa del monumental terreno circundante: el jugador se convierte en espectador.

La exploración del entorno en Assassin's Creed II se facilita, no solo por la visualización de este que proporciona el uso de la cámara, sino también por diferentes dispositivos de orientación y ayudas a la navegación. Parte de estos dispositivos se corresponden con los que King y Krzywinska (2006) recopilan a la hora de abordar la navegación en los videojuegos tridimensionales. Por una parte, en la esquina inferior derecha del videojuego de Ubisoft se muestra un mapa con los elementos interactivos y espaciales más cercanos al jugador, generalmente edificios y posiciones de amigos y/o enemigos. Estos mapas muestran partes del espacio del 
juego orientadas a la consecución de información requerida para progresar en el juego. También es posible guiarse por medio de una brújula que indica la distancia a la que el personaje se encuentra del objetivo, o el punto cardinal al que se dirige el jugador. Asimismo, a lo largo de los distintos niveles hay personajes no jugadores cuyas indicaciones permiten guiar al jugador hacia ciertos puntos del espacio del videojuego.

Continuando con la clara faceta espacial de Assassin's Creed II, King y Krzywinska (2006) indican que casi todos los videojuegos pueden caracterizarse por el equilibro ofrecido entre las restricciones creadas por las reglas y los objetivos del juego y las posibilidades permitidas para jugar alrededor de manera más libre dentro del mundo del juego. Assassin's Creed II estaría en este lugar intermedio. A la hora de hablar de esta dinámica entre las restricciones marcadas por las reglas del juego y la libertad de exploración es importante el concepto que proponen de agencia exploratoria, entendida como la posibilidad del jugador de poder decidir sobre el tipo de navegación que llevará a cabo en el espacio de un videojuego. Como señalan estos autores, la exploración está unida a la persecución de objetivos y misiones que hacen avanzar al jugador a través de los distintos niveles que propone el juego, pero también puede constituir un placer en sí mismo, al permitir el movimiento a través de una gran variedad de paisajes. Esta idea conecta, de nuevo, con la libertad que ofrece Assassin's Creed II de explorar las diferentes recreaciones de la Italia renacentista y de reconocer lugares populares como el Ponte Vecchio.

No obstante, la agencia exploratoria se suele limitar por razones que tienen que ver con la usabilidad o con el tipo de experiencia estética o sensación que se quiera transmitir al jugador. King y Krzywinska (2006) identifican dos tipos de restricciones que permiten a los diseñadores de juegos controlar el movimiento de los jugadores por el espacio interactivo. Por una parte, se encuentran las restricciones duras o barreras absolutas en el terreno de juego. Es el caso de las puertas que no se pueden abrir, o de los muros que el personaje del juego no puede saltar. Por otra, se encuentran las restricciones blandas, que actúan de manera temporal y pueden atravesarse bajo determinadas condiciones. Por ejemplo, en Assassin's Creed II hay terrenos que no pueden ser explorados hasta que el jugador cumple una serie de misiones determinadas. Una vez éstas han sido cumplidas, la restricción desaparece.

\section{ASSASSIN'S CREED: CINE DE ATRACCIONES}

En la película Assassin's Creed, el realizador Justin Kurzel sitúa al espectador en el año 1492. Callum Lynch (Michael Fassbender) se transporta a la España de finales del siglo XV, dominada por una poderosa Inquisición. La expansión transmedia trae, por tanto, localizaciones y personajes que no se abordan en la saga de videojuegos, y un mayor énfasis en el presente, que ocupa más espacio en la diégesis narrativa (concretamente en las salas de Industrias Abstergo, en Madrid). Y es desde 
este presente como la película, a través de un narrador en tercera persona, explica qué es la Hermandad de los Asesinos, de una forma consistente con respecto a lo que narra la saga de videojuegos, si bien se introducen algunas variaciones con respecto a lo que el jugador ha experimentado en el medio lúdico. Ejemplo de ello es el Animus, que deja de ser una camilla para convertirse en un sistema mecánico que conecta a Callum con su red neuronal y que provoca que los distintos recuerdos provenientes de su antepasado, Aguilar, lo posean hasta tal punto que Callum reproduce con su cuerpo los movimientos del antepasado invocado. Además, el Animus ya no es una tecnología de visualización, sino que conecta de una manera más vicaria a Callum con su antepasado, algo que le permite tomar mayor conciencia de su condición de Asesino.

Si bien la película rescata estos elementos definitorios de la saga, no hace lo mismo con los personajes. El espectador no accede a las memorias de Aguilar a través de un personaje ya conocido en la saga, como Desmond Miles. Callum Lynch es un Asesino que no aparece en la saga de videojuegos. Asimismo, su antepasado no transporta al espectador a las memorias de un personaje ya conocido, sino que lo hace hacia Aguilar, quien en 1492 lucha por alejar el Fruto del Edén de los Templarios dándoselo a Cristóbal Colón. La incorporación de Lynch denota necesidad por avanzar en todo proceso de trasvase desde un texto fuente.

Un elemento que la película rescata de manera especial de la saga de videojuegos es el sistema de valores que emerge del juego y que se recoge en el Credo . La película extrae elementos importantes de la saga de juegos al replicar los principales postulados de este código ético: cuando los hombres se limiten por la moral o la ley, todo está permitido; y los Asesinos actúan en las sombras para servir a la luz. La película también recoge el sistema de valores de los Templarios, que buscan controlar el mundo eliminando un derecho civil tan fundamental como es el libre albedrío, bajo la premisa de que al pueblo ya no le interesan los derechos civiles, sino su nivel de vida. El valor de actuar en las sombras se extrae también del videojuego a través del vestuario de los Asesinos de la película (que ensombrece y oculta parcialmente sus rostros), las armas ocultas bajo el brazo y la habilidad de actuar de manera sigilosa.

Desde el punto de vista de las affordances, la película hace posible observar desde fuera los componentes jugables de la saga de videojuegos, como las mecánicas de saltar de edificio en edificio haciendo parkour, luchar en azoteas, realizar el «salto de fe» o trepar para alcanzar la cima de las atalayas. Vinculado a la noción de affordance, Jaime Banks y Joe A. Wasserman (2019) investigan qué lleva a los fans de la saga de videojuegos Assassin's Creed a visionar la película de Kurzel partiendo de la transmedialidad y de la teoría de los usos y gratificaciones, que se centra en cómo los usuarios eligen deliberadamente los medios que, a su juicio, mejor pueden satisfacer sus necesidades. Partiendo de este enfoque, Banks y Wasserman señalan que determinadas affordances pueden promover 
diferentes gratificaciones. Mientras las gratificaciones que los videojuegos permiten obtener se asocian principalmente a la competición, el desafío y la diversión (Yee, 2006), las de las películas se vinculan con la relajación, la interacción social y el escape (Rubin, 1983). En el contexto específico de Assassin's Creed, Banks y Wasserman identificaron como gratificaciones obtenidas con relación a la película la expectativa de conectarse al universo de ficción a través de una plataforma distinta, con personajes y detalles nuevos. También la posibilidad de reforzar su identidad como fans de la saga. Asimismo, detectaron que para los jugadores que participaron en la investigación, la película ayudaría a legitimar la franquicia, en tanto que el cine goza de una imagen de superioridad cultural al concebirse como una fuente de educación e información, mientras que los videojuegos (a pesar de la vertiente educativa y persuasiva de los serious games) se suelen considerar esencialmente fuentes de entretenimiento.

Desde el punto de vista estético, la nueva versión del Animus denota una inquietud plástica por dotar a ciertos elementos de la película de mayor impacto visual que el que tienen en la saga de videojuegos. Esto manifiesta la voluntad de los creadores de la película de ofrecer algo más que una transferencia del videojuego. La inquietud por mostrar una mayor espectacularidad a través de efectos visuales se percibe también en el intento por extraer ciertos componentes jugables de la saga de videojuegos. Mecánicas como recorrer el entorno trepando, realizar el «salto de fe» o trepar para alcanzar la cima de las atalayas se transforman en planos de cuidado detalle pictórico y con la clara intención de deleitar visualmente al espectador. Ejemplo de ello son las vistas panorámicas que la película ofrece cuando Callum Lynch accede a un edificio de altura considerable en Madrid, en una suerte de imitación de los planos que ofrece el videojuego cuando el jugador alcanza una atalaya, o los planos generales donde es posible apreciar las diferentes acrobacias de Lynch al realizar parkour.

\section{ASSASSIN'S CREED REFLEXIONES \#1: CONMEMORACIÓN E INTERTEXTUALIDAD}

Assassin's Creed: Reflexiones, de Ian Edginton y Valeria Favoccia (guionista y dibujante, respectivamente) es una serie de cuatro historietas lanzada por Titan Comics en 2017 en conmemoración de los diez años del primer videojuego de la franquicia de Ubisoft. Estos cómics traen de vuelta a distintos protagonistas de los videojuegos, concretamente a Ezio Auditore, Altaï Ibn-La'Ahad, Connor Kenway y Edward Kenway, en una serie de historias que el lector descubre a través del Maestro Templario Otso Berg. En Assassin's Creed: Reflexiones \#1, Otso Berg se transporta al siglo XVI (año 1512) mediante el Animus para revivir los recuerdos de Ezio con el fin de dar con nuevas formas de implantar la doctrina templaria y obtener el control del mundo sin tener a la Hermandad de los Asesinos como obstáculo. 
A través de la experiencia de Otso Berg, el lector accede a un Ezio de edad avanzada que realiza una visita a su antiguo y ya anciano amigo Leonardo Da Vinci, que se encuentra agonizando. Durante esta visita Ezio desvela un secreto no conocido por los jugadores de la saga, y es que este mantuvo un romance con la Gioconda. El cómic desvela que el gesto de complicidad mantenido de la pintura original de Leonardo Da Vinci tiene que ver con la complicidad que esta guardó en un momento en que, mientras Da Vinci pintaba el cuadro, Ezio pasó por la misma sala.

Esta anécdota romántica de Ezio, hasta ahora no conocida por el jugador o fan de la saga, se inscribe de forma consistente en el mismo mundo de ficción que construyen los videojuegos. Al igual que sucede en estos, el lector accede a detalles de la historia a través de un personaje perteneciente a la época actual (Otso Berg), que conecta con los recuerdos de un Asesino de la Hermandad que le transporta a otro lugar (Italia) y a otro período histórico (Renacimiento). Este trasfondo narrativo permite al lector conectar con personajes que existieron en la realidad (Leonardo Da Vinci, la Gioconda), si bien con ciertas licencias de ficción. Un elemento que se diferencia con respecto a las historias de los videojuegos es que en el cómic quien accede a la memoria de un Asesino es un templario, en lugar de otro Asesino. La premisa inicial de la saga de videojuegos, que asume que un Asesino puede conectarse con sus antepasados, cambia en este cómic. El lector no está ante un Asesino, sino ante un templario que indaga en la Hermandad bajo la premisa de que la única forma de conocer a un enemigo es transformarse en él, para verse a uno mismo como el enemigo lo ve, con sus debilidades y fortalezas. La intención conmemorativa del cómic se observa claramente en expresiones de Otso: «si vamos a aprender de los enemigos que sea de los mejores».

De nuevo, y al igual que la película, el cómic extrae del videojuego la iconografía propia de las armas y la vestimenta de los Asesinos, con una especial atención en la hoja oculta bajo el brazo y las capas que ayudan a ensombrecer y ocultar parcialmente el rostro. Se trata de una vestimenta y armadura que, al igual que en los videojuegos, se asocia a la filosofía y principios de los Asesinos, especialmente en su lema de actuar en las sombras para servir a la luz.

Se suele considerar que la relación de sinergia existente entre cómics y videojuegos surge principalmente con el cómic como fuente original de la que parte y emerge el mundo de ficción, algo que aquí se produce de modo inverso, tanto en el film como en las historietas. Resulta más sencillo pensar en el videojuego como medio de expandir el mundo transmedia a través de la amplia multimodalidad que le caracteriza como medio (sistemas hápticos, banda sonora, imagen en movimiento, etc.), que considerar que el videojuego es el punto de partida del mundo transmedia y que un medio como el cómic, a través de imágenes y palabras, pueda amplificar el universo (Stemmler, 2021). Pero lo realiza exitosamente centrándose en proporcionar al lector, mediante una imagen 
bidimensional amable y colorista, detalles sobre uno de los personajes más queridos de la saga en un tono libre de tensión. No es la intención del cómic ser jugable, ni remitir a los aspectos más espectaculares del juego, tal y como hace la película (subidas a atalayas, «saltos de fe», etc.), pero sí ahonda en uno de los elementos del videojuego que forma parte de su imagen de marca, que es la posibilidad de volver a un lugar y período histórico ya visitado en la saga de videojuegos (concretamente, la saga de Ezio, que se concentra entre los juegos Assassin's Creed II, 2009; Assassin's Creed Brotherhood, 2010 y Assassin's Creed Revelations, 2011).

\section{CONCLUSIONES}

En este trabajo se ha abordado la expansión del universo de ficción de Assassin's Creed a través de la revisión de una muestra de creaciones de este universo. Se puede concluir con la idea de que videojuegos, película y cómics conviven en una lógica transmedia que permite sumergir con mayor profundidad al consumidor/usuario en un mundo ficcional cuya extensión crece a través de su interacción con dicho mundo y de la expansión del mythos, del topos y del ethos en diferentes plataformas para obtener una experiencia más completa y satisfactoria. Elementos narrativos clave en la franquicia y presentes en Assassin's Creed II (el Animus, la Hermandad) se llevan a otros formatos mediáticos donde se funden de manera coherente con localizaciones, personajes y momentos históricos diferentes (Madrid, La Inquisición Española, Asesinos que no aparecen en la saga de videojuegos), así como con anécdotas nuevas de personajes ya conocidos (Ezio en Assassin's Creed: Reflexiones \#1). En este contexto, resulta interesante observar cómo determinados aspectos que son jugables en el videojuego se convierten en elementos pertenecientes a la diégesis en otras plataformas o manifestaciones como el cine y los cómics.

El salto de Assassin's Creed a la gran pantalla se ha asociado con la idea de legitimación, lo cual podría vincularse a un intento, que debería ser innecesario, por hacer ver que este universo de ficción trasciende al juego y es «algo serio». Algo que va en consonancia con esta idea es que, si bien el videojuego está realizado en animación 3D, la película está realizada en imagen real con componentes de CGI (Computer Generated Imagery), tratando de llegar a un mayor número de audiencias. La imagen real legitima el atrevimiento de perpetrar un relato a partir del videojuego. Se trata de un complejo que debería estar superado.

El videojuego no suele ser el origen de un proyecto transmedia. No obstante, cada vez se van identificando más proyectos que optan por las IPs (propiedad intelectual) de los videojuegos para desarrollar este tipo de estrategias narrativas. Ejemplo de ello es la serie de animación realizada a partir del videojuego League of Legends (Riot Games, 2009). Esto es una señal de que el videojuego ya cuenta con ricos recursos y capacidad para crear IPs interesantes para otros medios tradicionalmente más legitimados y consolidados como el cine o el cómic. 


\section{BIBLIOGRAFÍA CITADA}

BAnKs, Jaime y Joe A. WASSERman (2019), «The big screen treatment: Gratifications sought in game-to-film transmedia consumption», Poetics, 73, págs. 72-83.

Bolter, Jay y Richard Grusin (2000), Remediation: Understanding New Media, Cambridge/Londres, The MIT Press.

Chalfoun, Pierre y Jonathan Dankoff (2018), «Developing actionable biometric insights for production teams», en A. Drachen, P. MirzaBabaei y L. Nacke (eds.), Games User Research, Nueva York, Oxford University Press, págs 301-322.

ECO, Umberto (1979), The Role of the Reader: Explorations in the Semiotics of Texts, Bloomington, Indiana University Press.

Herman, David (2002), Story Logic: problems and possibilities of narrative, Lincoln, University of Nebraska Press.

HutCHEON, Linda (2006), A Theory of Adaptation, New York, Routledge.

ISER, Wolfgang (1978), The Act of Reading: A Theory of Aesthetic Response, Baltimore, Johns Hopkins University Press.

JENKINS, Henry (2006), Convergence culture: where old and new media collide, Londres/Nueva York, New York University Press.

Jenkins, Henry (2004), "Game Design as Narrative Architecture», en N. Wardrip Fruin y P. Harrigan (eds.), First Person. New media as story, performance and game, Cambridge/Londres, The MIT Press, págs. 118-130.

KInG, Geoff y Tanya KRZYwinska (2006), Tomb Raiders \& Space Invaders. Videogame Forms \& Contexts, Londres/Nuevas York, I.B Tauris.

KING, Geoff y Tanya KrZYwinska (2002), Screenplay. Cinema/Videogames/Interfaces, Londres, Wallflower Press.

KLevjer, Rune (2002), «In Defense of Cutscenes», en F. Mäyrä (ed.), Proceedings of Computer Games and Digital Cultures Conference, Tampere, Tampere University Press, págs. 191-202.

Jurzel, Justin (2016), Assassin's Creed, Regency Enterprises Ubisoft, New Regency Pictures.

Manovich, Lev (2005), El lenguaje de los nuevos medios de comunicación, Barcelona, Paidós.

Murray, Janet (1999), Hamlet en la Holocubierta: el futuro de la narrativa en el ciberespacio, Barcelona, Paidós.

NaVArro, Víctor (2019), Cine ludens. 50 diálogos entre cine y juego, Barcelona, Editorial UOC.

NiTSCHE, Michael (2008), Video Game Spaces: Image, Play, and Structure in 3D Worlds, Cambridge/Londres, The MIT Press.

Nómada, Studio (2018), Gris. Devolver Digital.

PeArCe, Celia (2007), «Narrative environments. From Disneyland to World of Warcraft», en F. Borries, S. P Walz y M. Böltger (eds.), Space Time Play. Computer Games, Architecture and Urbanism: The Next Level, Basel/Boston/Berlín, Birkhäuser, págs. 44-55. 
RuBiN, Alan (1983), «Television uses and gratifications: The interactions of viewing patterns and motivations», Journal of Broadcasting \& Electronic Media, 27/1, 37-51.

ScOlari, Carlos Alberto (2019), Media Evolution. Sobre el orígen de las especies mediáticas, Buenos Aires, La Marca Editora.

SCOLARI, Carlos Alberto (2015), Ecología de los medios, Barcelona, Gedisa.

Scolari, Carlos Alberto (2013), Narrativas Transmedia. Cuando Todos los Medios Cuentan, Barcelona, Deusto.

Stemmler, Claudius (2021), «Metal Gear Solid and its comics adaptations», en A. Rauscher, D. Stein y J. N Thon, Comics and Videogames.From Hybrid Medialities to Transmedia Expansions, Londres / Nueva York, Routledge, págs 113-126.

SuCASAS, Ángel (2020), «El cómic le da el "Sí, quiero" al videojuego», El País, s. pág. [En línea: https://elpais.com/cultura/2020/01/31/ka_boom/1580431076_3 54411.amp.html. Fecha de consulta: 04/03/2020].

TosCA, Susana y Lisbeth Klastrup (2019), «An Experience Approach to Transmedia Fictions», en M. Freeman y R. Rampazzo Gambarato, The Routledge Companion to Transmedia Studies, Nueva York / Londres, Routledge, págs 392-400.

UBisoft (2007), Assassin's Creed I. Ubisoft.

UBISOFT (2009), Assassin's Creed II. Ubisoft.

UBisoft (2018), Assassin's Creed Oddyssey. Ubisoft.

Villalobos, José María (2016), Cine y videojuegos: Un diálogo transversal, Sevilla, Héroes de Papel.

Westin, Jonathan y Ragnar Hedlund (2016), «Polychronia. Negotiating the popular representation of a common past in Assassin's Creed», Journal of Gaming \& Virtual Worlds, 8/1, págs. 3-20.

YEE, Nick (2006), «Motivations for play in online games», CyberPsychology \&Behavior, 9/6, págs. 772-775.

Fecha de recepción: 10/04/21.

Fecha de aceptación: 07/05/21. 